\title{
Pupae of Mesozoic Oryctochlus Kalugina, 1985 (Chironomidae: Podonominae), with description of two new species
}

\author{
Elena D. Lukashevich'
}

Lukashevich ED. 2012. Pupae of Mesozoic Oryctochlus Kalugina, 1985 (Chironomidae: Podonominae), with description of two new species. Fauna norvegica 31: 159-165.

The Mesozoic Chironomidae are briefly reviewed. Two new species, Oryctochlus brundini n.sp. and O. kaluginae n.sp. from the Late Jurassic of Mongolia, are described based on pupae. The species of Oryctochlus known from pupae are photographed and keyed, their chaetotaxy is discussed.

doi: 10.5324/fn.v31i0.1400. Received: 2011-10-28. Accepted: 2012-06-26.

Published on paper and online: 2012-10-17.

Keywords: Chironomidae, Podonominae, fossil, new species, SEM

1. Borissiak Paleontological Institute RAS, Profsoyuznaya ul. 123, 117997 Moscow, Russia

E-mail: elukashevich@hotmail.com

\section{INTRODUCTION}

Fossil Chironomidae are abundant but relatively little studied. They are known from all three periods of the Mesozoic (Triassic, Jurassic and Cretaceous). The greater the age, the lower the diversity and abundance of chironomids, and the scantier our knowledge of them.

So far, there is no evidence that the role of chironomids in Triassic and Early Jurassic ecosystems was as significant as in the later periods. The earliest chironomid, Aenne triassica Krzeminski \& Jarzembowski, 1999, is known by a single isolated wing from the Late Triassic of the United Kingdom; the type species of this genus, A. liasina Ansorge, 1999, is described from the Early Jurassic of Germany (Ansorge 1999; Krzeminski \& Jarzembowski 1999). Recent research on deposits of these periods provided no or very little new data on the early history of the family. A. triassica still remains the only undoubted Triassic chironomid. Immature chironomids from the Triassic and Early Jurassic remain unknown.

Some two dozen chironomid genera have been described from the Jurassic, and about the same number of genera is known from the Cretaceous. In the Jurassic, the subfamilies Aenneinae, Ulaiinae, Podonominae, and Tanypodinae are recorded, all from Eurasia. Some of the Jurassic genera remain poorly studied. Cretaceous chironomids are recorded also from Australia, North and South America (including a number of undescribed specimens) and are represented by, in addition to the subfamilies known since the Jurassic, Prodiamesinae,
Diamesinae, Orthocladiinae, and possibly Buchonomyiinae. With exception of Manlayamyia Kalugina, 1980, Cretaceous chironomid genera are adult-based taxa. The vast majority of Cretaceous chironomids have been described from Lebanese amber and other fossil resins from Canada, Siberia and Great Britain. Therefore, their descriptions follow the standards used in the systematics of extant midges (Evenhuis 1994; Jarzembowski et al. 2008; Azar et al. 2008). Kalugina (1974) examined many hundreds of impressions and amber inclusions from the Mesozoic of Russia and demonstrated that Chironominae were absent until the Late Cretaceous (where they are exceptionally rare). The subfamily is absent in the now well-studied Early Cretaceous Lebanese amber (Azar \& Nel 2010).

Almost our entire knowledge of Mesozoic chironomid immatures, which often dominate fossil assemblages, consists of the descriptions of pupae and larvae from Asia by Kalugina (Kalugina \& Kovalev 1985; Kalugina 1993). In the only other paper with descriptions of Mesozoic chironomid immatures, the pupae were identified only to subfamily (Jell \& Duncan 1986).

The type species of genus Oryctochlus Kalugina, 1985 was established based on numerous impressions of various life history stages from the locality of Uda in Transbaikalia (Middle or Late Jurassic). Additional members of the genus were later described by Kalugina from the Late Jurassic or Early Cretaceous of Transbaikalia (Ukurey, Tergen' and Glushkovo Formations) based on scarce immatures (Kalugina 1993). 
Only a few adults of this genus are known, all from Eurasia (Zhang 1991; Ansorge 1996). Pupae of Oryctochlus are easily recognizable by the shape and chaetotaxy of their abdominal segments VIII and IX (see below). In particular, this allows us to determine that members of this genus are absent among numerous pupae from the Cretaceous of Australia figured by Jell \& Duncan (1986). However, adults of this genus are less distinctive, which leads to some uncertainty in the generic placement of species described based on adults only $(O$. affinis Kalugina, 1985, O. minutus Kalugina, 1985, O. contiguus Zhang, 1991, ?O. toarciensis Ansorge, 1996).

The genus was originally attributed to Podonominae, but recently Veltz et al. (2007) considered all Podonominae described by Kalugina as Chironomidae incertae sedis. This point of view cannot be accepted (for detailed arguments see Lukashevich \& Przhiboro 2011). Kalugina pointed out that differentiation between the Mesozoic Podonominae and Tanypodinae is difficult, probably because these two subfamilies were less clearly distinguished morphologically in the Jurassic (Kalugina \& Kovalev 1985: 82). This, however, does not apply to Oryctochlus: pupal morphology eliminates any doubts as to its placement.

In the present study all type specimens of the species known as pupae are re-examined and keyed and photographs of some of them are published herein for the first time. The adult and larval characters of these species are not discussed. The generic diagnosis is modified after Kalugina. Two new species of Oryctochlus are described below, each based on a single pupa, from the Upper Jurassic lacustrine deposits of Shar Teg Beds, SW Mongolia (for details on the geographic position and unique fossil flora and fauna of that locality, see Gubin \& Sinitza 1996). Recently, several chironomid species have been described based on adults from Shar Teg, but members of Oryctochlus are not found among numerous impressions of adults, possibly because of their poor preservation (Lukashevich \& Przhiboro 2011).

All fossils mentioned below are housed in Borissiak Paleontological Institute, Russian Academy of Sciences, Moscow (PIN). Photographs were taken using a Leica M165C stereomicroscope equipped with a Leica DFC425 digital camera, with subsequent adjustments made using the Adobe Photoshop ${ }^{\circledR}$ CS 9.0 software. Scanning electron micrographs of intact specimens were taken on a Tescan Vega XMU instrument using a backscattered electron detector (BSE). For further details regarding fossil localities, see Rasnitsyn \& Quicke (2002).

\section{SYSTEMATICS}

\section{Family Chironomidae Newman, 1834}

\section{Subfamily Podonominae Thienemann \& Edwards, 1937}

In the Jurassic deposits of Siberia this is the dominant Chironomidae subfamily in terms of both specimen abundance and diversity (Kalugina \& Kovalev 1985); no relevant data are available for other regions.

\section{Genus Oryctochlus Kalugina, 1985}

Oryctochlus Kalugina in Kalugina \& Kovalev 1985: 83. Type species Oryctochlus vulcanus Kalugina in Kalugina \& Kovalev, 1985: 85, fig. 40, Tab. IV, figures 1-7.

\section{Diagnosis}

Pupa medium sized, up to $6 \mathrm{~mm}$ long, cephalothorax mostly darker than abdomen, exuvia very pale. Thoracic horn well developed, large, subequal to abdominal segments in length, longer than wide, ovoid or cylindrical, slightly expanded, distally round, with small to medium plastron plate, horn membrane sometimes reticulate. All leg sheaths under wing sheath, meeting at tip of wing sheath, distal portion of fore- and midleg sheaths practically straight, S-shaped portion of hind leg sheath beneath distal half of wing sheath. Abdominal segments II-VII simply quadrangular, subequal in size, with apophyses present also on segment VIII. Segment VIII with apicolateral lobes enveloping basal part of segment IX. Segment VIII with 5 usually large straight or slightly wavy lateral setae (LS), anterior one situated before apicolateral lobes, segment IX with 3 shorter subequal lateral setae, 2 close together in mid-section and 1 on anal lobe. Segment IX with 2 broad apically pointed anal lobes, at least sometimes with apical setae, sometimes with small denticles on apical half of outer margin. Male genital sac narrow and pointed, reaching to end of anal lobe, female genital sac shorter and roundish, median margins of genital sacs confluent along entire length.

\section{Composition}

Besides new species, nine species from the Jurassic (and possibly Early Cretaceous) of Eurasia; pupae were known for only five species.

Figure I. Pupae of Oryctochlus spp. A, I, N, O: O. vulcanus Kalugina, 1985. A, I: Holotype. A: Abdominal apex. I: Thoracic horn. N: Chaetotaxy of segments VIII and IX, right side, combined based on positive (PIN 3053/959) and negative (PIN 3053/979) impressions of paratype. O: paratype PIN 3053/959, chaetotaxy of segment IX, left side. B, C, K: O. longilobus Kalugina, 1985, holotype. B, $\mathrm{C}$ : Abdominal apex, enlarged portion of outer margin. K: thoracic horn. D: O. minor Kalugina, 1985, holotype, abdominal apex. All

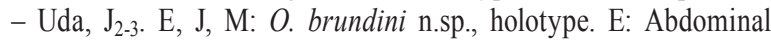
apex. J: Thoracic horn. M: Total view. F: O. kaluginae n.sp., holotype, abdominal apex. Both - Shar Teg, J3. G, H, L: O. mirificus Kalugina, 1993. G: Paratype PIN 4043/8, abdominal apex, Volchya, $\mathrm{J}_{3}-\mathrm{K}_{1}$. H: Holotype, cephalotorax, Unda, $\mathrm{J}_{3}-\mathrm{K}_{1}$. L. Paratype PIN $3795 / 1098$, thoracic horn, Shevia, $\mathrm{J}_{3}-\mathrm{K}_{1}$. Arrow marks visible apex of seta on anal lobe. Photo: Elena Lukashevich. 


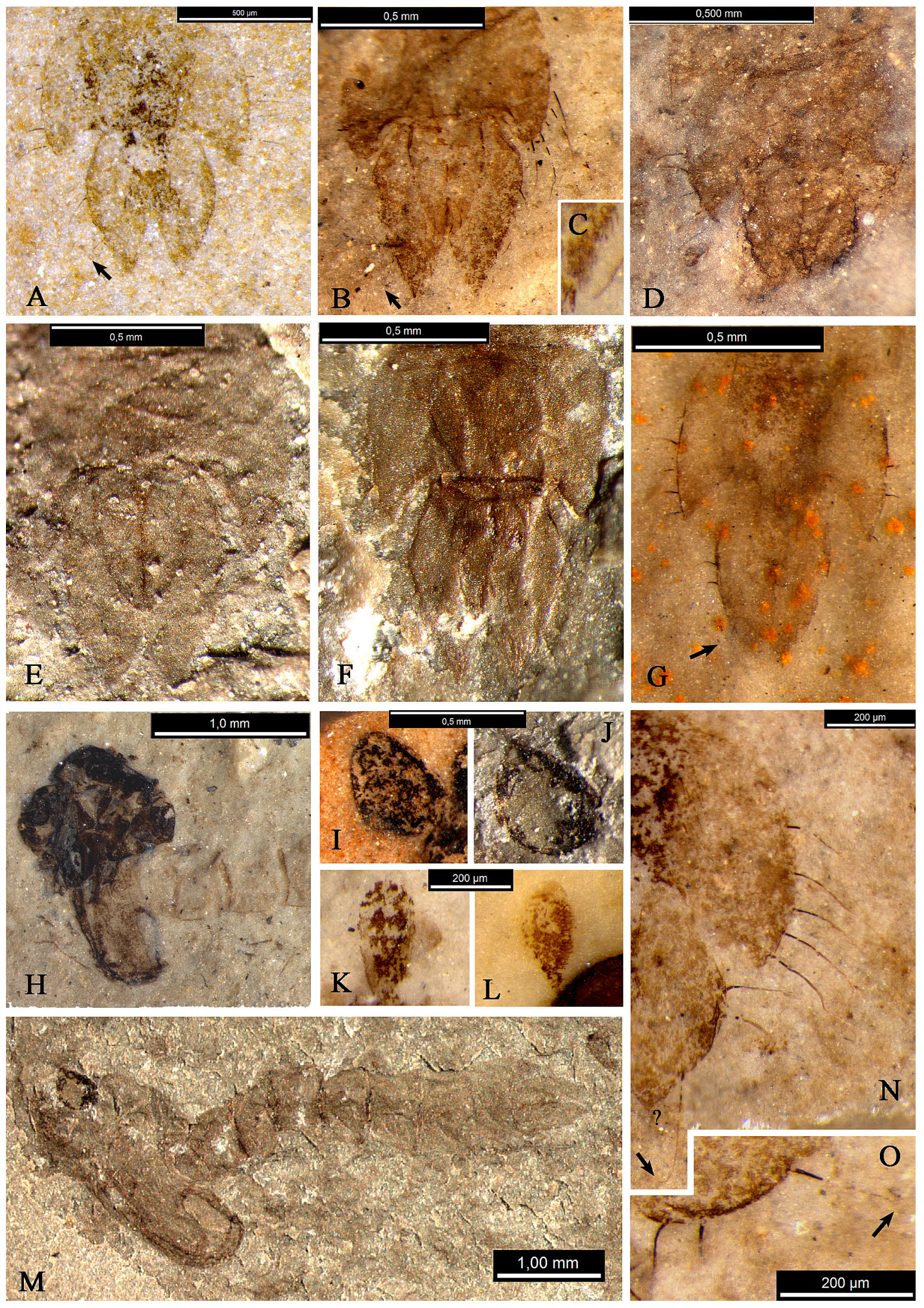




\section{Remarks}

The pupa of the genus is distinguished from that of all other known Mesozoic species by the shape of the segment VIII and arrangement of lateral setae on the segment IX. In these characters it resembles only the pupae of recent Trichotanypus Kieffer, 1906, from which it differs by the shape of the thoracic horn, straight or sligthly wavy lateral setae, which are not restricted to the apicolateral lobe on segment VIII, and sometimes by the apically pointed anal lobes, possibly, without small straight apical setae.

\section{Key to known pupae of Oryctochlus species}

1 (6) Thoracic horn large, ovoid, 1.5x as long as wide, 0.3-0.7x as wide as segment VIII (Figures 1I, J, 3C)

2 (3) Apicolateral lobes of segment VIII long, about 2/5 of total length, enveloping almost half of segment IX (Figures 1E, M, 2A, B) O. brundini n.sp.

(Shar Teg, J )

3 (2) Apicolateral lobes of segment VIII shorter, enveloping no more than $1 / 3$ of segment IX

4 (5) Anterior LS setae at 0.5 length of segment VIII, sternites with sharply delineated apophyses, anal lobe outer margins with small denticles (Figures 2C, D, 3A, B) O. kaluginae n.sp.

(Shar Teg, $\mathrm{J}_{3}$ )

5 (4) Anterior LS setae at 0.4 length from base of segment VIII, apophyses very thin, anal lobe without denticles (Figures 1A, N, $\mathrm{O}, 2 \mathrm{E})$ O. vulcanus Kalugina, 1985 (Uda, Uda Formation, $\mathrm{J}_{2}-\mathrm{J}_{3}$ ) 6 (1) Thoracic horn slender, cylindrical, slightly expanded, distally round, $2-3 \mathrm{x}$ as long as wide, $0.15-0.25 \mathrm{x}$ as wide as segment VIII (Figures 1K, L)

7 (8) Segment VIII only 1.5x as wide as segment IX, anal lobe with small denticles on outer margins and strongly divergent inner margins (Figures 1B, C, 2F)

$$
\text { O. longilobus Kalugina, } 1985
$$

(Uda, Uda Formation, $\mathrm{J}_{2}-\mathrm{J}_{3}$ )

8 (7) Segment VIII 2x as wide as segment IX, anal lobe without denticles on outer margins and with slightly divergent inner margins (last character not studied in 0 . minor)

9 (12) Apicolateral lobes of segment VIII pointed, long, about $2 / 5$ of total length, enveloping almost half of segment IX, anterior LS setae at 0.5 length from base of segment VIII 10 (11) Segment IX rounded, as long as wide (Figure 1D) O. minor Kalugina, 1985

(Uda, Uda Formation, $\mathrm{J}_{2}-\mathrm{J}_{3}$ )

11 (10) Segment IX elongate (Figures 1G, H)

O. mirificus Kalugina, 1993

(Unda, Volch'ya, Glushkovo Formation, Shevia, Ukurei Formation, Tergen', Tergen' Formation, $\mathrm{J}_{3}-\mathrm{K}_{1}$ )

12 (9) Apicolateral lobes of segment VIII rounded, shorter, enveloping no more than $1 / 3$ of segment IX, anterior LS setae at 0.3 length from base of segment VIII

O. placidus Kalugina, 1993

(Olov Depression, Ukurey Formation, $\mathrm{J}_{3}-\mathrm{K}_{1}$ )

\section{Oryctochlus brundini n. sp.}

\section{Material examined}

Holotype: PIN 4270/2343 (well-preserved exuvium); SW Mongolia, Shar Teg (outcrop 434/2); Late Jurassic.

Diagnosis (Figures 1E, J, 2A, B, 3C)

Measurement (mm). Total length 5.7; anal lobe length 0.75, width 0.26 ; thoracic horn length 0.47 , width 0.33 . Exuvium pale, uniformly coloured. Thoracic horn dark, large, ovoid, $1.5 \mathrm{x}$ as long as wide, broadest near base, $0.7 \mathrm{x}$ as wide as segment IX and $0.3 \mathrm{x}$ as wide as segment VIII, plastron plate small. Wing sheaths wide, without nose, not tapering. Sternites with sharply delineated apophyses. Abdominal chaetotaxy not preserved. Apicolateral lobes of segment VIII long, about 2/5 of total length, enveloping almost half of segment IX. Anal lobe elongated, $2.8 \mathrm{x}$ as long as wide, anal lobe with strongly divergent inner margins. Genital sacs of female reaching $2 / 3$ of anal lobe length.

\section{Remarks}

The new species is close to O. minor and O. mirificus in the shape of segment VIII (Figures 1 D, G), but differs from these species in the shape of thoracic horn (Figure 1L) and in the inner margins of anal lobe being strongly divergent.

\section{Etymology}

Named in the memory of L. Brundin, an outstanding Swedish expert in Chironomidae.

\section{Oryctochlus kaluginae $\mathrm{n}$. sp.}

\section{Material examined}

Holotype: PIN4270/2442 (well-preserved pupa); SW Mongolia, Shar Teg (outcrop 443/1); Late Jurassic.

Diagnosis (Figures 1F, 2C, D, 3A, B)

Measurements (mm). Total length 5.6, anal lobe length 0.6, width 0.25 , thoracic horn length 0.7 , width 0.5 . Pupa light brown, uniformly coloured (cephalothorax sligthly darker with dark leg sheaths). Thoracic horn (incompletely preserved) large, approximately $1.4 \mathrm{x}$ as long as wide, subequal to segment IX width, $0.7 \mathrm{x}$ as wide as segment VIII. Wing sheaths wide, without nose, not tapering. Sternites II-VIII with sharply delineated apophyses. Apicolateral lobes of segment VIII short, about $1 / 5$ of total length, enveloping $1 / 6$ of segment IX. Anterior LS setae at 0.5 length from base of VIII segment. Anal lobe elongated, 2.4x as long as wide, with strongly divergent inner margins, outer margins with small denticles. Genital sacs of females not reaching $2 / 3$ of anal lobe length, ending beyond to distal of two setae in mid-section.

\section{Remarks}

The new species is close to O. longilobus (Figures 1B, C, K) in the shapes of segments VIII and IX, the chaetotaxy, and the presence of small denticles on the anal lobe outer margins but is different in the shape of thoracic horns. 

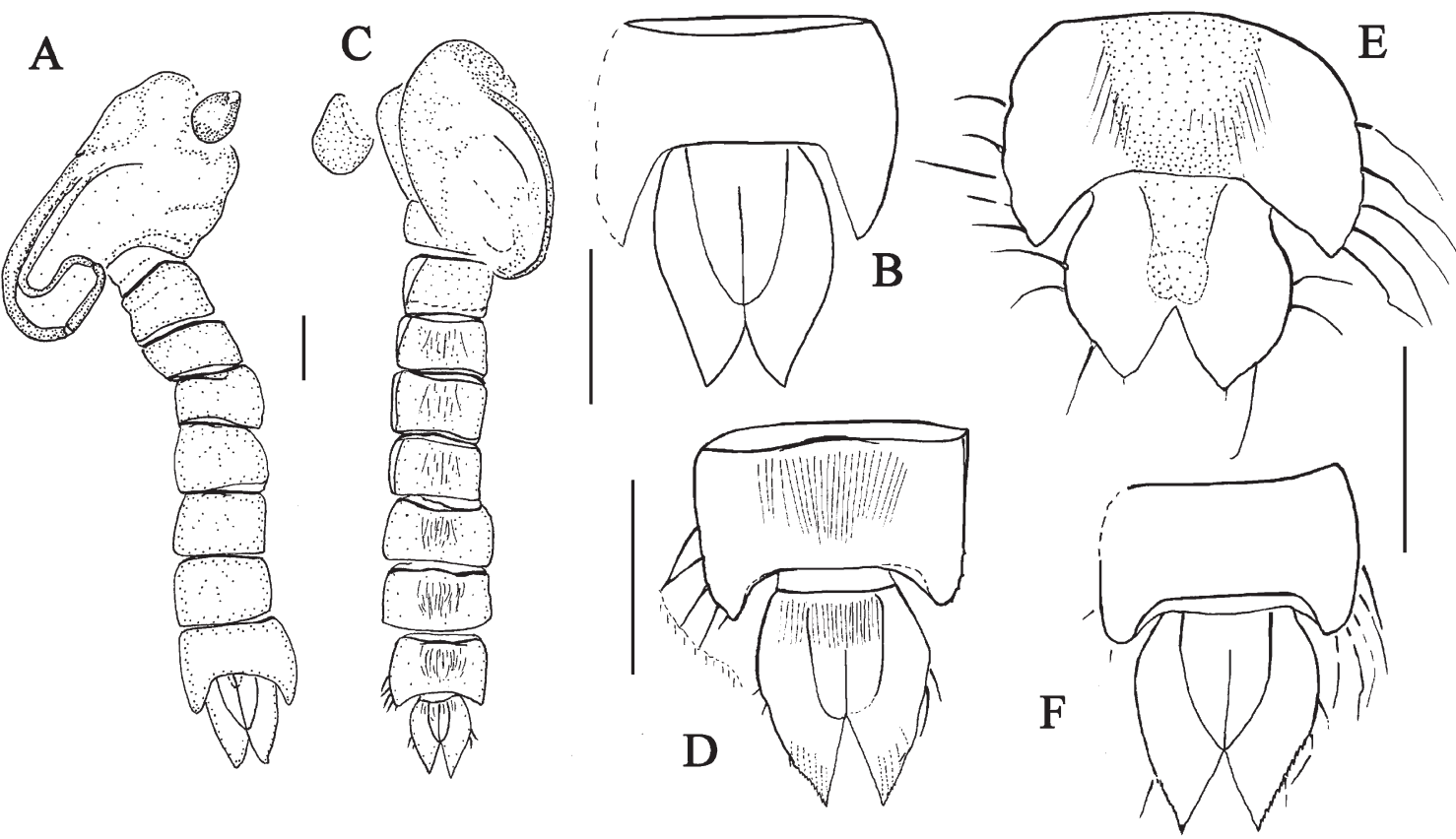

Figure 2. Pupae of Jurassic Oryctochlus spp. A, B: O. brundini n.sp., holotype. A: Total view. B: Abdominal apex. C, D: O. kaluginae n.sp., holotype. C: Total view. D: Abdominal apex. Both-Shar Teg, J3. E: O. vulcanus Kalugina, 1985, paratype PIN 3053/959, abdominal apex, combined based on positive and negative (PIN 3053/979) impressions. F: O. longilobus Kalugina, 1985, holotype, abdominal apex. Both - Uda, $\mathrm{J}_{2 / 3}$. Scale bar $0.5 \mathrm{~mm}$.
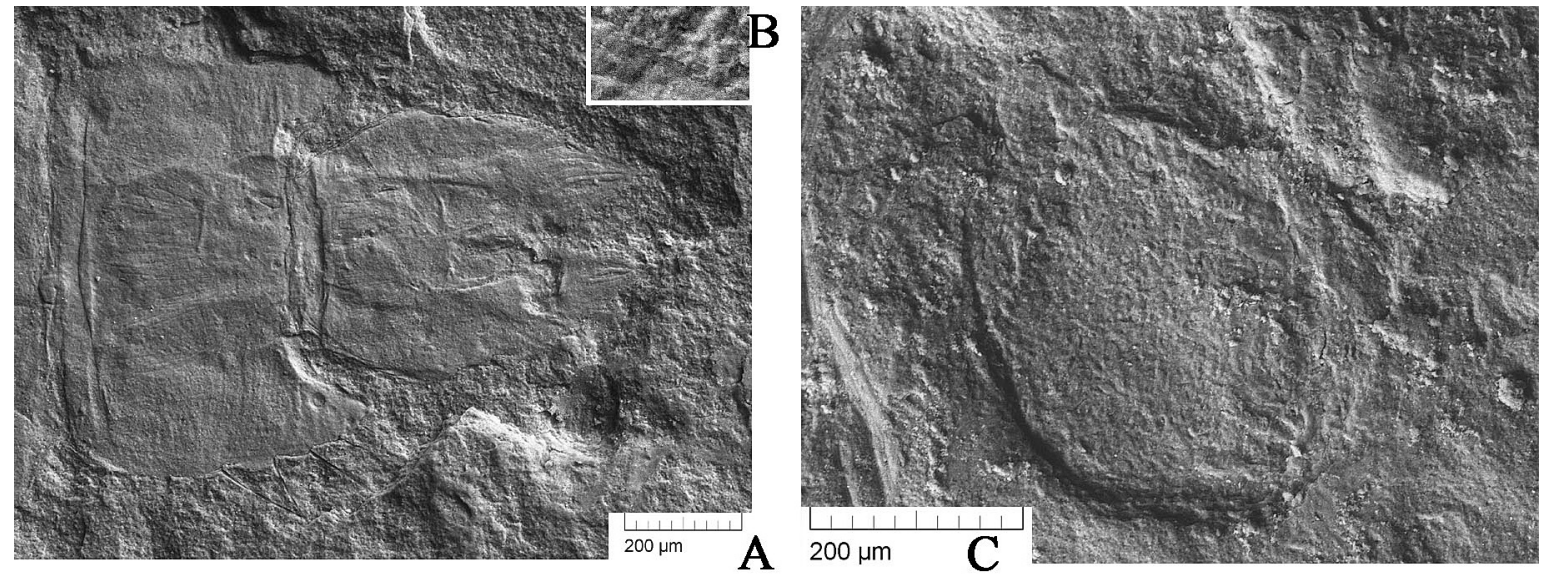

Figure 3. SEM of Oryctochlus spp. pupae from Shar Teg, $\mathrm{J}_{3}$. A, B: O. kaluginae n.sp., holotype. A: Abdominal apex. B: Denticles on anal lobe outer margin. C: O. brundini n.sp., holotype, thoracic horn. Photo: Roman Rakitov.

\section{Etymology}

Named in the memory of N.S. Kalugina, an outstanding Russian paleoentomologist.

\section{DISCUSSION}

More than a hundred impressions of adult and immature Oryctochlus have been found at the type locality of Uda, indicating that the genus is lacustrine (Kalugina \& Kovalev
1985). Among numerous impressions of Oryctochlus vulcanus Kalugina found larvae with translucent thoracic horns and pupae with translucent male genitalia, which allowed to confidently associate the larvae and pupae and, with some doubts, the pupae and adults. Kalugina compared every life stage of Oryctochlus with those of recent Trichotanypus and drew the conclusion of undoubted affinity of these two podonomine genera, based mainly (but not exclusively) on the peculiar shape of the pupal segments VIII and IX and their chaetotaxy. Among characters of other life history stages, the 
larvae of $O$. vulcanus have very long procerci (almost 10x as long as wide), typical of Podonominae. It is worth mentioning that a recent time-calibrated molecular phylogenetic study has recovered Trichotanypus as one of the oldest recent podonomine genera, which split off from Parochlini in the Early Cretaceous (Cranston et al. 2010).

Re-examination of the type material confirmed the podonomine affinity of Oryctochlus, proposed by Kalugina. This assignment is based first of all on the presence of a plastron plate on the thoracic horn and the arrangement of leg sheaths (all leg sheaths under wing sheath, meeting at tip of wing sheath, distal portion of fore- and midleg sheaths practically straight, S-shaped portion of hind leg sheath beneath distal half of wing sheath - Figures $1 \mathrm{H}, \mathrm{M}$ ). This combination of characters, included by Kalugina in the generic diagnosis, is diagnostic of the subfamily Podonominae (Brundin 1986). However, the key evidence is the chaetotaxy of segment IX, which is similar among extant midges only to Trichotanypus. In fact, the segment IX with two broad, apically pointed anal lobes is characteristic not only of Podonominae but also of Tanypodinae (e.g. Telopelopia Roback, 1971), and such shape of the segment VIII, with a concave posterior margin, is known not only in podonomine Trichotanypus and Podonomopsis but also in tanypodine Tanypus Meigen, 1803 and prodiamesine Odontomesa Pagast, 1947. Nevertheless, the anal lobe chaetotaxy patterns of Prodiamesinae and Tanypodinae are quite different: in the former the lobe bears a fringe of lamelliform setae and 3-5 anal macrosetae, grouped in the distal portion of the lobe, whereas in the latter it always lacks distal macrosetae, bearing only two anal macrosetae in the mid-section, sometimes combined with a fringe (Fittkau \& Murray 1986; Saether 1986). Additionally, in Prodiamesinae the thoracic horn has no plastron plate and the leg sheath arrangement is different.

Brundin (1976: 144) described the basic synapomorphy of Podonominae as follows: "Abdominal segments VIII and IX of the pupa in the basic design with strongly enlarged lateral setae which are more or less sharply bent two times in the proximal half and ending in a hook, there being primary $5+5$ of these "wavy setae" on segment VIII, $3+3$ on segment IX". In Trichotanypus the wavy setae are weakly developed: "the two bends are only slightly indicated, and the hook-shaped terminal portion is slenderer than the rest of the setae" (Brundin 1966: 314). Moreover, within the genus their structure also varies: in T. posticalis (Lundbeck, 1898) they are very long, subequal to the length of segment VIII, and distinctly wavy (Brundin 1966: fig. 443), in T. hanseni Wirth \& Sublette, 1970 they are shorter (2/3 as long as segment VIII), with two setae in the mid-section of segment IX almost straight (Wirth \& Sublette 1970: fig. 6), and in T. arctoalpinus Makartshenko, 1983 they are shorter yet (only half as long as segment VIII) and only slightly wavy (some appear straight: Makarchenko 1985: fig. 52).

In her original diagnosis of Oryctochlus Kalugina (1985: 84) wrote about "not long, straight or only slightly curved, not wavy, dark lateral setae" and used this character to distinguish the genus from Trichotanypus. My re-examination of the type material has allowed refining the diagnosis. In fact usually one can see only dark, thick proximal parts of setae, which are straight (Figures 1F, 3A) or slightly curved (Figures 1A, D, G) (see diagnosis), and only occasionally the setae are entirely visible. The specimen PIN 3053/997 was selected as a holotype of $O$. vulcanus because it shows a pair of thoracic horns attached to the pupa. However, the chaetotaxy is much better preserved on the paratype PIN 3053/959 (negative impression PIN 3053/979; Figures 1A, N, O, 2E). On the segment VIII of that specimen one can see slightly curved long (half as long as segment VIII) setae with thin pale distal part and some of them appear slightly wavy. It is possible that the segment IX bears, besides 3 long lateral setae ( 2 curved and 1 straight), small straight apical setae (marked with "?" on the Figure 1N) which are obvious on the paratypes PIN 3053/982, 1049 as in Trichotanypus. Even the presence of "black zones" basally on the setae, as recorded in some Trichotanypus and Podonomopsis Brundin, 1966 (Brundin 1966), can be tentatively surmised for O. vulcanus (Figure 10). The original figure of the $O$. longilobus holotype appears to be inaccurate (Kalugina \& Kovalev 1985: fig. 43): the lateral setae on the segment VIII are in fact much longer (half as long as the segment VIII) and some seem to be slightly wavy (Figures $1 \mathrm{~B}, 2 \mathrm{~F})$, very similar to those of $T$. arctoalpinus. Moreover, in both species the anal lobe outer margins are armed with small denticles. Therefore, in the chaetotaxy of the segments VIII and IX the Mesozoic Oryctochlus and the recent Trichotanypus are more similar than was previously supposed (although the lateral setae of the segment VIII of Oryctochlus are not restricted to the apicolateral lobe as in Trichotanypus) and only the shapes of their thoracic horns are strongly different.

It is worth to mention that, within Trichotanypus, the pupae of different species also differ from each other in the shape of their thoracic horns (the stalk enlarged basally in T. posticalis and tapering proximally in T. hanseni) and occurrence of apical marginal denticles (present in T. posticalis and T. arctoalpinus, absent in T. hanseni). Both broad and slender thoracic horns also occur in some other podonomine genera such as Podochlus Brundin, 1966.

Admittedly, the thoracic horns of Oryctochlus differ from any figured by Brundin (1966) for Podonominae. He considered the thoracic horns of some species of Parochlus Enderlein, 1912, with the stalk strongly sclerotized, straight and tapering proximally and the plastron plate well-developed, widened distally as the most plesiomorphic. Only the thoracic horn structure of $O$. longilobus (Figure $1 \mathrm{~K}$ ), with the plastron plate poorly visible, can fit this description, but it is more likely that its horn is not trumpet-shaped but distally round with a moderate plastron plate. In other species of Oryctochlus the plastron plate appears not as large, and the widest part of the horn is not apical (incidentally, as in Trichotanypus). However, because thoracic horns vary strongly within this subfamily these differences may be of little importance. Within recent Parochlus one can find not only the "ideal plesiomorphic" horns but also very peculiar 
horns of $P$. tubulicornis Brundin, 1966, tapering distally, with a very slender bent stalk and small, strongly reduced plastron plate at the rather narrow tip (similar to the very small plastron plate on the thoracic horn of Trichotanypus posticalis).

Therefore, contrary to Veltz et al. (2007), there are no reasons to doubt the podonomine affinity of Oryctochlus.

\section{ACKNOWLEDGMENTS}

I am deeply indebted to Dmitry Shcherbakov (Paleontological Institute RAS, Moscow) and Andrey Przhiboro (Zoological Institute RAS, St.Petersburg) for valuable discussion and Roman Rakitov (Paleontological Institute RAS, Moscow) for assistance in taking scanning electron images and proofreading the manuscript. I also thank to anonymous reviewers for valuable comments on the early manuscript. The research was partly supported by the program of the Presidium of the Russian Academy of Sciences "Biosphere origin and evolution of geobiological systems".

\section{REFERENCES}

Ansorge J. 1996. Insekten aus dem oberen Lias von Grimmen (Vorpommern, Norddeutschland). Neue Palaontologische Abhandlungen 2: 1-132.

Ansorge J. 1999. Aenne liasina gen. et sp. n. - the most primitive non biting midge (Diptera: Chironomidae: Aenneinae subfam. n.) from the Lower Jurassic of Germany. Polskie Pismo Entomologiczne 68: 431-443.

Azar D, Veltz I, Nel A. 2008. Mandibulate chironomids: primitive or derived? (Diptera: Chironomidae). Systematic Entomology 33: 688-699.

Azar D, Nel A. 2010. Two new non-biting midges from the Early Cretaceous Lebanese amber (Diptera: Chironomidae). Annales de la Société Entomologique de France (n.s.) 46(1-2): 198-203.

Brundin L. 1966. Transantarctic relationships and their significance, as evidenced by chironomid midges with a monograph of the subfamilies Podonominae and Aphroteniinae and the austral Heptagyiae. Kungliga Svenska Vetenskapsakademiens Handlingar 11: 1- 472 .

Brundin L. 1976. A Neocomian chironomid and PodonominaeAphroteniinae (Diptera) in the light of phylogenetics and biogeography. Zoologica Scripta 5: 139-160.

Brundin L. 1986. 4. The pupae of Podonominae (Diptera: Chironomidae) of the Holarctic region - Keys and diagnoses. In: Wiederholm T. (ed.). Chironomidae of the Holarctic region. Keys and diagnoses. Part 2. Pupae. Entomologica Scandinavica Supplement 28: 19-30.

Cranston PS, Hardy NB, Morse GE, Puslednik L, McCluen SR. 2010. When molecules and morphology concur: the "Gondwanan" midges (Diptera: Chironomidae). Systematic Entomology 35: 636-648.

Evenhuis NL. 1994. Catalogue of the fossil flies of the world (Insecta: Diptera). Leiden. Backhuys Publishers. $600 \mathrm{p}$.

Fittkau EJ, Murray DA. 1986. 5.The pupae of Tanypodinae (Diptera:
Chironomidae) of the Holarctic region - Keys and diagnoses. In: Wiederholm T. (ed.). Chironomidae of the Holarctic region. Keys and diagnoses. Part 2. Pupae. Entomologica Scandinavica Supplement 28: 31-113.

Gubin YM, Sinitza SM. 1996. Shar Teg: a unique Mesozoic locality of Asia. Museum of Northern Arizona Bulletin 60: 311-318.

Jarzembowski EA, Azar D, Nel A. 2008 A new chironomid (Insecta: Diptera) from Wealden amber (Lower Cretaceous) of the Isle of Wight (UK). Geologica Acta 6(3): 285-291.

Jell PA, Duncan PM. 1986. Invertebrates, mainly insects, from the freshwater, Lower Cretaceous, Koonwarra Fossil Bed (Korumburra Group), South Gippsland, Victoria. Memoir of the Association of Australasian Palaeontologists 3: 111-205.

Kalugina NS. 1974. Changes in the subfamily composition of chironomids (Diptera, Chironomidae) as indicators of a possible eutrophication of bodies of water during the Late Mesozoic. Bulleten MOIP (otdelenie Biologia). 79(6): 45-56. [in Russian]

Kalugina NS. 1993. Chaoborids and midges from the Mesozoic of Eastern Transbaikalia (Diptera: Chaoboridae and Chironomidae). In Ponomarenko AG. (ed.) Mesozoic insects and ostracods from Asia. Trudy PIN 252: 117-139. [in Russian].

Kalugina NS, Kovalev VG. 1985. Jurassic Diptera of Siberia. Moscow. Nauka. 198 p. [In Russian]

Krzeminski W, Jarzembowski E. 1999. Aenne triassica sp.n., the oldest representative of the family Chironomidae (Insecta: Diptera). Polskie Pismo Entomologiczne 68: 445-449.

Lukashevich ED, Przhiboro AA. 2011. New Chironomidae (Diptera) with elongate proboscises from the Late Jurassic of Mongolia. In Shcherbakov D., Engel M., Sharkey M. (eds.) Advances in the Systematics of Fossil and Modern Insects: Honouring Alexandr Rasnitsyn. Zookeys 130: 307-322.

Makarchenko EA. 1985. Chironomidae of the Far East of the USSR. Subfamilies Podonominae, Diamesinae and Prodiamesinae (Diptera, Chironomidae). Vladivostok. Far Eastern Research Center of the USSR Academy of Sciences. $200 \mathrm{p}$.

Rasnitsyn AP, Quicke LJ. 2002. History of insects. Dordrecht, Boston, London. Kluwer Academic Publishers. 517 p.

Saether OA. 1986. 8.The pupae of Prodiamesinae (Diptera: Chironomidae) of the Holarctic region - Keys and diagnoses. In: Wiederholm T. (ed.). Chironomidae of the Holarctic region. Keys and diagnoses. Part 2. Pupae. Entomologica Scandinavica Supplement 28: 139-145.

Veltz I., Azar D., Nel A. 2007. New chironomid flies in Early Cretaceous Lebanese amber (Diptera: Chironomidae). African Invertabrates 48(1): 169-191.

Wirth WW, Sublette JE. 1970. A review of the Podonominae of North America with descriptions of three new species of Trichotanypus (Diptera: Chironomidae). Journal of Kansas Entomological Society 43 (4): 335-354.

Zhang J. 1991. New geners and new species of Chironomidae (Diptera, Insecta) from Late Jurassic of China. Acta Paleontologica. Sinica 30(5): 556 -569. 